\title{
Crianças como sujeitos de direitos: uma revisáo de literatura sobre crianças em situação de acolhimento institucional
}

\author{
Thais Pacheco Epifânio ${ }^{a}$, Monica Villaça Gonçalves ${ }^{\mathrm{b}}$ \\ aUniversidade Federal do Rio de Janeiro - UFRJ, Rio de Janeiro, RJ, Brasil.

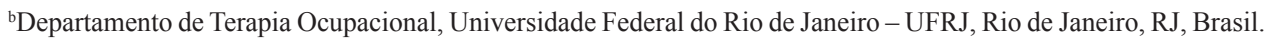

\begin{abstract}
Resumo: Introdução: Este trabalho tem como temática o contexto de crianças nos abrigos e seus direitos, depois da implementação do Estatuto da Criança e do Adolescente (ECA) em 1990. Objetivo: Analisar o conteúdo de artigos cujas temáticas abordaram crianças em situação de abrigamento à luz das orientações propostas pelo ECA. Método: Foi realizada uma revisão sistemática na base de dados LILACS com os descritores "criança institucionalizada" or "abrigo" or "abrigo social", utilizando como idioma o português. Foram encontrados 111 artigos, dos quais 92 foram excluídos após a leitura do resumo, por não se adequarem aos critérios da pesquisa. Dos 19 artigos que foram lidos integralmente, mais 5 foram descartados por não se adequarem ao tema, restando 14 artigos para análise. Resultados: Após análise dos textos foram identificadas três categorias a partir dos temas recorrentes e relacionados à questão da pesquisa: "O abrigo como instituição com características de instituições totais", "Os abrigos em relação ao que preconiza o ECA" e "O estigma de crianças abrigadas: sujeitos de direitos ou massa assujeitada?". Foi observado que a descrição dos abrigos não está em consonância com a lei, com muitas semelhanças com o antigo modelo de abrigamento, despreparo dos profissionais e desconhecimento das atuais leis, resultando numa visão das crianças como objetos de tutela do Estado. Conclusão: Conclui-se a necessidade de capacitação dos profissionais envolvidos no processo de acolhimento institucional e um empoderamento e conscientização sobre direitos.
\end{abstract}

Palavras-chave: Criança Institucionalizada, Abrigo, Defesa da Criança e do Adolescente, Revisão do Estado da Arte.

\section{Children as subjectos endowed with right: a systematic review of children in situation of institutional care}

\begin{abstract}
Introduction: This study addresses the context of children in shelters and their rights after the implementation of the Child and Adolescent Statute (Estatuto da Criança e do Adolescente - ECA) in 1990. Objective: To analyze the content of articles approaching children in situation of institutional care in the view of the guidelines proposed by ECA. Method: A systematic review was carried out in the LILACS database using the following descriptors: "institutionalized child" or "shelter" or "social shelter", in Portuguese language. A total of 111 articles were found, of which 92 were excluded after reading the abstract as they did not meet the selection criteria set in the research. After reading the 19 remaining articles in full length, 5 were eliminated because they did not address the theme under study. Thus, 14 articles were used in the analysis. Results: After selection of relevant articles for research and analysis of content, three categories of analysis, based on the recurrent themes of the texts and their relation to the present research theme, were identified: "Shelters as institutions with complete institutional characteristics", "Shelters and their stance in relation to ECA recommendations" and "The stigma of sheltered children: subjects with rights or subjugated mass?". The description of shelters is evidently not in consonance with the law, but clearly resembles the old model of sheltering, with unpreparedness and lack of knowledge of laws from the part of
\end{abstract}

Autor para correspondência: Monica Villaça Gonçalves, Centro de Ciências da Saúde, R. Prof. Rodolpho Paulo Rocco, s/n, bloco K, sala k17, $1^{\circ}$. andar, Cidade Universitária, Ilha do Fundão, CEP 21910-590, Rio de Janeiro, RJ, Brasil, e-mail: movillaca@hotmail.com

Recebido em Mar. 15, 2016; $1^{\text {a }}$ Revisão em Jul. 1, 2016; 2ª Revisão em Nov. 17, 2016; Aceito em Fev. $21,2017$. 
professionals. This leads children to be viewed as objects of custody of the State. Conclusion: There is an evident need for training the professionals involved in the process of institutional shelter and also the need for raising empowerment and awareness of the rights of children in society.

Keywords: Child Institutionalized, Shelter, Children Rights, Review Literature as Topic.

\section{Introdução}

O Estatuto da Criança e Adolescente (ECA) surge como o primeiro mecanismo legal exclusivo à populaçáo de crianças e adolescentes, com a doutrina de proteção integral. O ECA preconiza que garantir os direitos de todas as crianças e adolescentes deve ser prioridade absoluta da família, da comunidade, da sociedade e do poder público (BRASIL, 1990).

Essa mudança de paradigma representa muitas transformaçóes, principalmente para a parcela da população infantil antes chamada de "menores em situação irregular", ou seja, crianças em situação de vulnerabilidade social, vítimas de violência, que cometeram atos infracionais ou que estão em situação de acolhimento institucional. Elas deixaram de ser "objetos de tutela" do Estado para serem "sujeitos de direito".

O abrigo, antes uma instituição total, punitiva, massificadora e permanente, muitas vezes sendo lugar de permanência das crianças e adolescentes até os 18 anos, passa a ser uma "[...] medida provisória e excepcional, utilizável como forma de transição para a colocação em família substituta, não implicando em privação de liberdade [...]" (BRASIL, 1990, p. 38).

\section{Por Que O Abrigamento Infantil É Uma Questão?}

Mais de 20 anos depois da instituição do ECA, é importante levantar questionamentos sobre até que ponto as mudanças foram feitas e a lei está sendo cumprida.

Os sistemas de saúde e de assistência social têm realizado ações higienistas e sem comprometimento com os reais objetivos dos abrigos, com uma visão que remete à década de 1970 e ao "problema do menor internado" por meio "[...] de um discurso científico que justifica a segregação de reededucação, da 'cura' [...]" (BARROS; LOPES; GALHEIGO, 2007, p. 348).

Muitos são os estigmas relacionados às crianças abrigadas. Goffman (1980) explica que a sociedade estabelece meios de categorizar pessoas e o total de atributos considerados comuns e naturais para os membros de uma determinada categoria, o que o autor chama de "identidade social". Essa identidade social faz com que, quando um estranho nos é apresentado, já tenhamos uma série de atributos esperados para essa pessoa. Quando esses atributos são negativos ou depreciativos, temos o que o ator nomeou de estigma. As crianças em situação de abrigamento/institucionalizaçáo geralmente são retratadas por suas características negativas como tristeza, insegurança, baixa autoestima, dificuldades no aprendizado, mau comportamento, agressividade, entre tantas outras. Ayres et al. (2010) confirmam esse pressuposto, ao afirmar em sua revisão que "[...] o simples fato de estar abrigado já comprometeria o pleno desenvolvimento do individuo [...]" (AYRES et al., 2010, p. 423) e ainda que "[...] se demarca um lugar específico de segregaçáo para a criança com relação àquelas não abrigadas [...]" (AYRES et al., 2010, p. 426). Segundo as autoras, esse estigma com relação às crianças abrigadas é um proceso histórico, sendo o Código de Menores uma representação importante dessa concepção das crianças institucionalizadas, uma vez que

[...] estes estabelecimentos eram voltados para crianças pobres, em um momento em que pobreza e abandono já eram prontamente transformados em perigo para a sociedade [...] (AYRES et al., 2010, p. 429).

Não se pode negar a existência dessas características em muitas crianças abrigadas. Em geral, elas passaram por experiências como abandono, vivência na rua, violência doméstica, além de muitas terem vivido grande parte de sua vida entre abrigos e lidando com situaçôes como falta de individualidade e quebras de vínculos. Entretanto, é importante não reduzir essas crianças a apenas essas características, esquecendo o fato de que ainda são crianças.

O ECA náo considera como direito da criança somente direitos básicos como à saúde, ao abrigo, à alimentação e à educação. Ele também dispóe sobe os direitos de ser criança, de ter liberdade de opiinão, expressão, crença e culto religioso, brincar, praticar esportes, divertir-se, participar da vida familiar e comutária, sem discriminação, e buscar refúgio, auxílio e orientação (BRASIL, 1990).

Entretanto, observam-se nos abrigos muitos resquícios das antigas instituiçôes que abrigavam os “menores em situação irregular". Infelizmente, o que tem acontecido é que, ao se tornarem "crianças 
abrigadas", a criança é afastada do convívio familiar e comunitário, passando entáo a ser estigmatizada pela sociedade e ignorada pelo poder pùblico.

Esse tipo de tratamento nos abrigos cria corpos tutelados, crianças sem direito a autonomia, a voz e opinião, e sem conhecimento de seus direitos.

A terapia ocupacional, ao sair da lógica saúde/doença nas discussóes sobre o papel técnico desse profissional na década de 1970, entra como um ator social importante na promoção dos direitos das crianças em situaçáo de acolhimento (BARROS; LOPES; GALHEIGO, 2007).

As intervençôes no campo da terapia ocupacional social acontecem junto ao indivíduo, para que este reconheça seus direitos e tome consciência de seu protagonismo em sua própria história. $\mathrm{O}$ foco das açóes passa a ser nas coletividades e relaçóes estabelecidas por esse indivíduo nesses coletivos (BARROS; LOPES; GALHEIGO, 2007) e devem ser levadas ao contexto do sujeito. No caso das crianças abrigadas, as ações, além do acompanhamento junto à criança, perpassam todo o cotidiano institucional e territorial da criança, entendida como um sujeito de direitos.

Discutir esse assunto pode possibilitar uma reflexão acerca do panorama que se tem no Brasil hoje e sobre possibilidades de mudanças efetivas na lógica atual do acolhimento infantil.

\section{Objetivo}

Analisar o conteúdo de artigos cuja temática aborda crianças em situação de abrigamento à luz das orientaçôes propostas pelo ECA.

\section{Método}

Realizou-se uma busca na base de dados LILACS com os seguintes Descritores em Ciências da Saúde (DeCS): "criança institucionalizada" or "abrigo" or "abrigo social", em março de 2014. Por ter como foco a situação de crianças, a busca não utilizou o descritor "adolescente".

Optou-se por selecionar apenas artigos em português e sem restrição de ano. A investigação está embasada no ECA e nas leis brasileiras, não sendo de interesse para a pesquisa artigos de outras nacionalidades. Para poder observar as mudanças da concepção com o passar do tempo, não se restringiu $\mathrm{o}$ ano de publicação. Entretanto, o acesso a artigos anteriores à promulgação do ECA foi restrito.
Selecionaram-se os artigos que fossem pesquisas de campo relacionadas ao período de acolhimento institucional da criança, com o objetivo de entender as concepçôes sobre crianças no cotidiano do abrigo.

Foram, portanto, utilizados os seguintes critérios de seleção de artigos:

- publicados em português;

- metodologia de pesquisa de campo;

- disponíveis na íntegra;

- tratassem do cotidiano de crianças em situação de abrigamento.

Como resultado, obtiveram-se 111 artigos. Após a leitura dos resumos, foram excluídos 92 artigos, pois não atendiam os critérios da pesquisa.

Foram encontrados 18 artigos que datam de antes de 1990, ou seja, antes da promulgação do ECA. Apesar de 8 deles se enquadrarem no tema, nenhum estava disponível integralmene para consulta online, não entrando portanto nesta pesquisa.

Dessa forma, restaram 19 textos, que passaram por uma leitura para análise inicial. Após esta, foram descartados 5 artigos que não tinham relação com o tema da pesquisa.

Os 14 artigos restantes foram lidos e analisados.

Após a leitura dos textos, foram elencadas 03 categorias de discussão a partir dos temas recorrentes a todos os textos e com relaçáo ao objetivo da pesquisa, sendo estas: "O abrigo como instituição com características de instituiçôes totais", "Os abrigos em relação ao que preconiza o ECA" e "O estigma de crianças abrigadas: sujeitos de direitos ou massa assujeitada?”.

\section{Resultados e Discussão}

Os 14 artigos selecionados para análise foram publicados entre os anos 2001 e 2011, com maior predominância de publicaçóes a partir de 2008 (9 artigos). Como não houve restrição de datas, é importante observar que as publicaçóes ocorreram em um período muito restrito (Tabela 1).

Além disso, é interessante observar que a partir de 2008 tivemos uma intensificação dessas publicações. Umas das possíveis explicaçôes é que, no ano de 2006, se instituiu o Plano Nacional de Promoção, Proteção e Defesa do Direito de Crianças e Adolescentes à Convivência Familiar e Comunitária (PNCFC), que complementa e regulariza a garantia de direitos já enunciados pela Constituição Federal de 1988, 


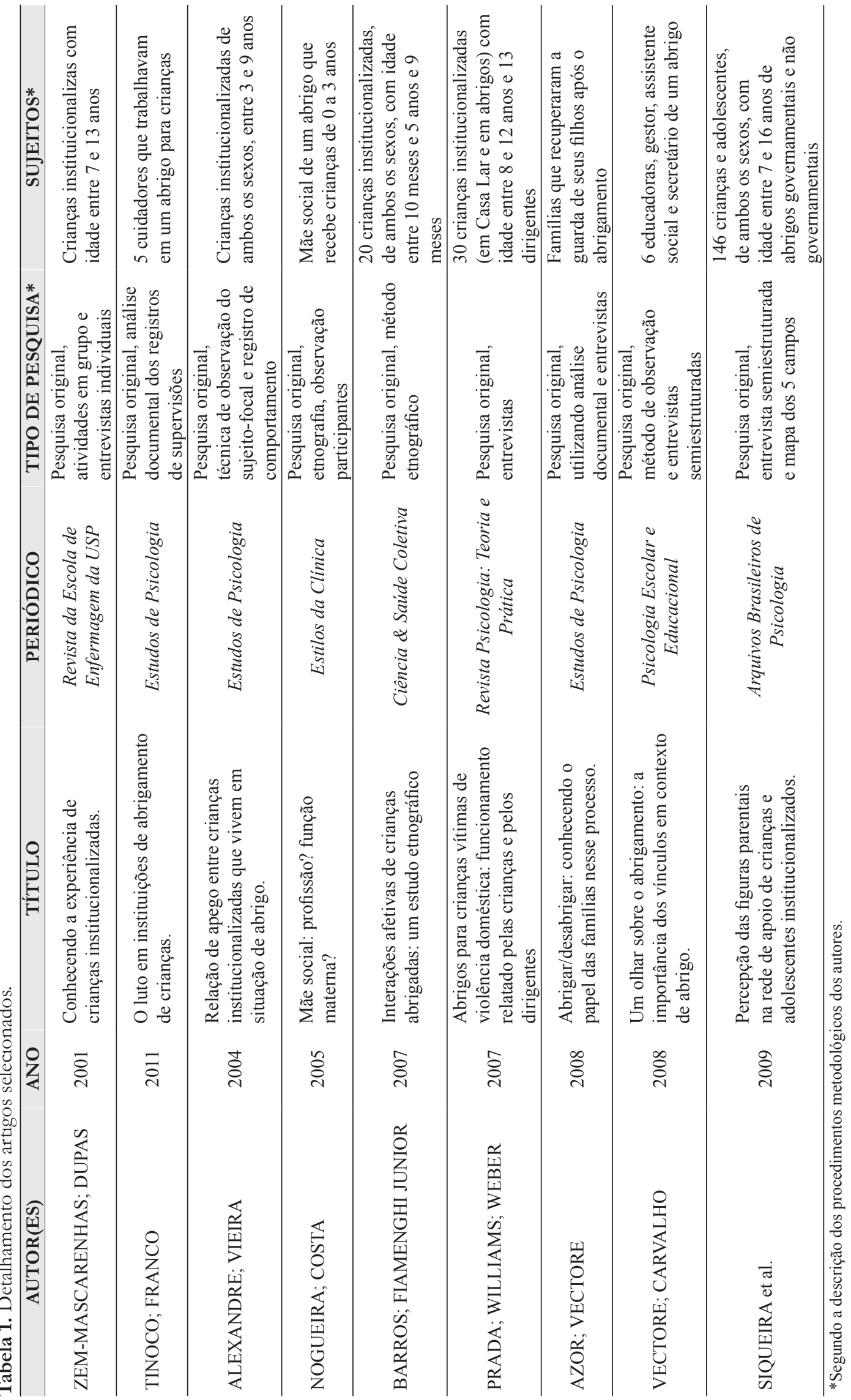




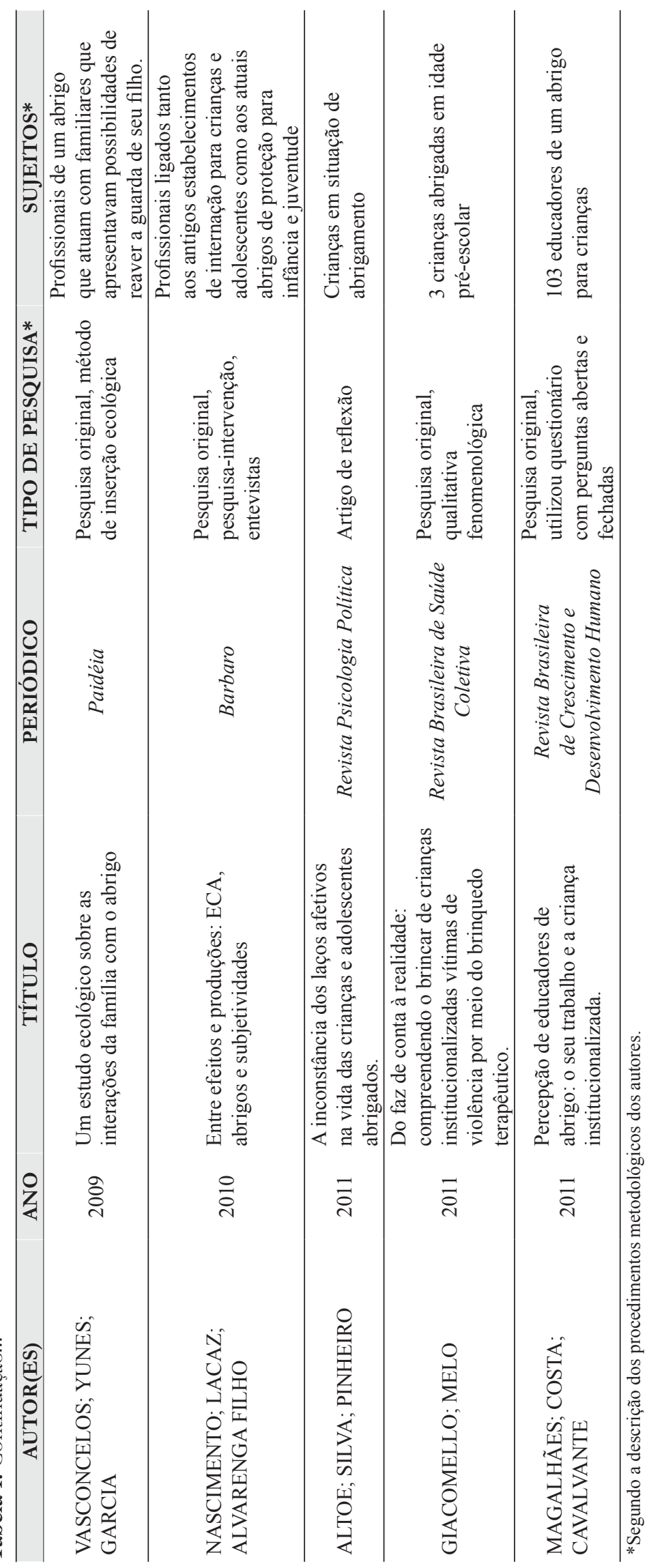


pelo ECA (BRASIL, 1990) e pela Lei Orgânica da Assistencia Social de 1993 (NERY, 2010). O PNCFC ressalta as novas discussóes e consideraçóes para o processo de acolhimento institucional, propondo uma mudança de paradigma em relaçáo à abordagem feita anteriormente, na vigência do Código de Menores, período em que as crianças abrigadas, compreendidas como "menores em situação irregular", não dispunham de um aparato legal que garantisse seus direitos.

Em relação à área de atuação do pesquisador, a maioria (10 artigos) é da área de psicologia, os outros sáo de enfermagem e multiprofissionais. As Orientaçóes Técnicas para os Serviços de Acolhimento de Crianças e Adolescentes (BRASIL, 2008), do Conselho Nacional dos Direitos da Criança e do Adolescente (CONANDA), estabelecem que as equipes técnicas de abrigos institucionais e de Casas Lares devem ser compostas de assistentes sociais e psicólogos.

Uma possível justificativa para a não obtençáo de publicações de assistentes sociais e pedagogos é o fato de a pesquisa ter sido realizada em uma base de dados da área da saúde (LILACS). Entretanto, a pesquisa de Malfitano e Silva (2014), também relacionada ao abrigamento infantil, que inclui Biblioteca Virtual de Ciências Humanas (BVCH), só encontrou 1 artigo nessa base.

Os terapeutas ocupacionais são profissionais de grande importância no processo de acolhimento institucional, entretanto, não foram encontrados artigos dessa área na busca, mesmo com as duas revistas nacionais de terapia ocupacional (Cadernos de Terapia Ocupacional da UFSCar e Revista de Terapia Ocupacional da USP), estando indexadas nessa base. Sabemos, entretanto, que é possível encontrar o tema de crianças e adolescentes em abrigo nas publicaçôes dessa área. Pensamos que essa ausência pode se dar pelo uso de descritores diferentes dos utilizados na pesquisa.

Após minuciosa leitura dos artigos selecionados, foram definidas 03 categorias temáticas, apresentadas e discutidas a seguir.

\subsection{O abrigo como instituição com características de instituições totais}

Dos artigos encontrados, 11 apresentavam diversas caractérísticas de instituiçôes totais ao relatar o cotidiano dos abrigos (ZEM-MASCARENHAS; DUPAS, 2001; NOGUEIRA; COSTA, 2005; BARROS; FIAMENGHI JUNIOR, 2007; PRADA; WILLIAMS; WEBER, 2007; VECTORE; CARVALHO, 2008;
AZOR; VECTORE, 2008; SIQUEIRA et al., 2009; NASCIMENTO; LACAZ; ALVARENGA FILHO, 2010; GIACOMELLO; MELO, 2011; MAGALHÁES; COSTA; CAVALCANTE, 2011; ALTOE; SILVA; PINHEIRO, 2011).

Goffman (2001, p. 11) definiu instituição total como:

[...] um local de residência e trabalho onde um grande número de indivíduos com situação semelhante, separados da sociedade mais ampla por considerável período de tempo, levam a vida fechada e formalmente administrada.

De acordo com o que preconiza o ECA, essas características não deveriam ser encontradas nos abrigos. Nas Orientaçōes Técnicas para os Serviços de Acolhimento para Crianças e Adolescentes (BRASIL, 2008) são apresentados alguns princípios que norteiam o acolhimento institucional, tais como: provisoriedade do afastamento do convívio familiar, preservação e fortalecimentos dos vínculos familiares e comuntários, oferta de atendimento personalizado e individualizado, entre outros.

Entretanto, em alguns dos trabalhos analisados, os autores (GIACOMELLO; MELO, 2011; NASCIMENTO; LACAZ; ALVARENGA FILHO, 2010) observam o fato de que nem sempre o que está na lei é cumprido.

O discurso predominante nas entrevistas nos falava constantemente da permanência de práticas referentes à lógica de internação nos abrigos. Isto é, apesar de o ECA ter sido promulgado no ano de 1990, a proposta se encontra distante da realidade dos abrigamentos, abrindo espaço para pensarmos que o abrigo tem sido um dispositivo tanto protetor quanto violador dos propalados direitos da criança e do adolescente, já que, apesar de protegê-los de situaçóes que causam dano, infringe a lei por outros percursos (NASCIMENTO; LACAZ; ALVARENGA FILHO, 2010, p. 54).

Goffman (2001, p. 17) descreve algumas caraterísticas que podem ser observadas em instituiçóes totais. Porém, menciona que essas características não são observadas exclusivamente em instituiçóes totais, e que nem todas as instituições vão compartilhar todos esses fatores. Ele diz que "[...] o que distingue as instituiçôes totais é o fato de cada uma delas apresentar, em grau intenso, muitos itens dessa família de atributos".

Este autor afirma ainda que as instituições totais têm como característica a divisão e a distância entre a equipe dirigente e os internos. A primeira estipula 
as regras e as controla para atender aos objetivos oficiais da instituição. Já os internos, ao serem subordinados a essas regras e rotinas, passam por um processo de "desculturamento", ou seja, perdem seu contato com o mundo externo e, consequentemente, com sua cultura e sua identidade. A identidade dos internados é mortificada pela padronização, pela falta de privacidade. Nas instituiçóes totais, os internos têm suas atividades cotidianas controladas, sofrem interferência, perdem seu poder de decisão, e com isso muitas vezes, para não criar problemas com a equipe dirigente, abdicam de sua individualidade (GOFFMAN, 2001).

Sobre a hierarquização entre equipe dirigente e internados, nos abrigos para crianças encontramos uma cultura semelhante, como no relatado por Giacomello e Melo (2011, p. 1577):

[...] revela a existência de uma violência institucional, onde a cultura de poder e dominação por parte dos "educadores" do abrigo impera.

Ao destinar esse tratamento às crianças, os cuidadores desrespeitam o ECA e a criança, distorcem a função do abrigo, tornam a experiência do abrigamento negativa para as crianças e criam um ambiente desfavorável ao desenvolvimento saudável das mesmas.

Outra associação observada entre as características dos abrigos descritas nos trabalhos analisados e as características descritas por Goffman é o fato de que a instituição total possui um caráter de fechamento, com proibiçóes de saída, onde todos os aspectos da vida são realizados no mesmo lugar, sempre com um grupo relativamente grande, tratados da mesma maneira e com regras e horários muito rígidos.

Os autores citam o fato de muitas vezes o abrigo se localizar em um local isolado (NASCIMENTO; LACAZ; ALVARENGA FILHO, 2010), onde todas as atividades, como assistência médica, odontológica, cursos, aulas de música, são realizadas no espaço da instituição (VECTORE; CARVALHO, 2008), e a saída acontece somento no momento de ir à escola (PRADA; WILLIAMS; WEBER, 2007). As crianças e adolescentes entrevistados nos artigos se queixam do fato de se sentirem trancados, sem possibilidades de participação comunitária fora do ambiente do abrigo (ZEM-MASCARENHAS; DUPAS, 2001; AZOR; VECTORE, 2008).

Como já visto anteriormente, são direitos da criança a liberdade e a participação comunitária. Está claro, pelo relato dos autores, que a participação comunitária dessas crianças não é um exercício cotidiano.
Em outro momento, as pesquisas relatam que, no abrigo, as crianças não existem como indivíduos, e sim como massa, com identidade e necessidades únicas para a instituição, sem direitos de fazer escolhas ou de ter privacidade (MAGALHÃES; COSTA; CAVALCANTE, 2011; PRADA; WILLIAMS; WEBER, 2007).

No tocante a percepção das educadoras acerca das características do ambiente institucional, observa-se que dois terços das educadoras concordam que a criança institucionalizada vive em condiçôes contextuais pouco favoráveis à liberdade de fazer escolhas sobre questóes práticas do seu dia-a-dia (72,55\%), ou mesmo, sem o direito a gozar de espaço pessoal e privacidade (66,67\%) (MAGALHÁES; COSTA; CAVALCANTE, 2011, p. 823).

As atividades rigorosamente estabelecidas em horários foi um tema muito recorrente na fala de crianças e trabalhadores dos abrigos. Foram descritas rotinas rígidas, com horários de levantar, tomar banho, escovar os dentes, arrumar quarto, comer, brincar e dormir, sem flexibilidade ou espaço para discussão (GIACOMELLO; MELO, 2011; ZEM-MASCARENHAS; DUPAS, 2001; VECTORE; CARVALHO, 2008; NOGUEIRA; COSTA, 2005; AZOR; VECTORE, 2008).

... é diferente, porque aqui tem hora prá tudo. Lá em casa ninguém ligava prá hora (A).

Sete horas, ai escova os dentes, arruma a cama, vai para o PROVIN (reforço escolar), depois toca o sino, sobe para tomar banho, vai para a escola. Ai depois vem da escola, janta, sobe, troca de roupa, fica na recreação e depois vai para o estudo. Depois do estudo você dorme (LA) (ZEM-MASCARENHAS; DUPAS, 2001, p. 417, grifo do autor).

Essa falta de liberdade e de poder de decisáo sobre vários aspectos do cotidiano aparece também ao ser tratado o assunto da posse de objetos pessoais. Em muitos casos, ao chegar ao abrigo, os objetos pessoais, roupas, brinquedos, tudo que é trazido consigo lhe é tirado e fica na guarda dos educadores, ou viram propriedade da instituição e são compartilhados por todos (ALTOE; SILVA; PINHEIRO, 2011; NASCIMENTO; LACAZ; ALVARENGA FILHO, 2010; PRADA; WILLIAMS; WEBER, 2007; NOGUEIRA; COSTA, 2005).

Prada, Williams e Weber (2007), em sua pesquisa em um abrigo com 30 crianças, constataram que nenhuma criança possui roupas próprias, que apenas 
$8 \%$ tinham seus próprios brinquedos e somente $25 \%$ delas tinham qualquer tipo de objeto pessoal.

Goffman (2001) afirma que os bens individuais têm uma relação muito grande com a identidade, já que as pessoas atribuem sentimentos àquilo que possuem e, ao serem despidas desses bens, sentem-se passando por um processo de desconfiguração pessoal. Diversos autores compartilham essa ideia, afirmando que o abrigo náo oferece características que preservem a singularidade do abrigado (ALTOE; SILVA; PINHEIRO, 2011), e que, ao lhe ser negado o direito que ter seus próprios objetos pessoais, ele perde sua liberdade e autonomia para cuidar de seus objetos e fazer escolhas (NASCIMENTO; LACAZ; ALVARENGA FILHO, 2010).

Na pesquisa de Magalhăes, Costa e Cavalcante (2011), $72,5 \%$ dos 102 educadores de abrigo entrevistados concordam que a criança institucionalizada vive em condições contextuais pouco favoráveis para fazer escolhas em seu dia a dia, e outros $66,7 \%$ que elas não gozam de espaços pessoais ou privacidade. Zem-Mascarenhas e Dupas (2001) concordam com essa afirmação e dizem que as crianças não escolhem o quê, com quem e quando realizam ou não as atividades do dia a dia mais simples, como tomar banho, fazer a tarefa ou brincar.

A opiniăo e a escolha das crianças não são consultada ou respeitada em outros momentos, como na organização das casas e dos quartos nos abrigos (VECTORE; CARVALHO, 2008), nos momentos de sair a passeio com pessoas desconhecidas (PRADA; WILLIAMS; WEBER, 2007) ou na decisão de ser levada para um abrigo (ZEM-MASCARENHAS; DUPAS, 2001), e este fato pode causar estranheza, medo e sofrimento. Entretanto, quando as decisóes e mudanças são planejadas e executadas junto aos abrigados, observa-se que eles se sentem mais seguros e capazes de se adaptarem a elas (TINOCO; FRANCO, 2011).

Ao observar todas essas características, é possível ver claramente que, apesar da iniciativa jurídica com o ECA de se afastar o máximo possível do modelo de instituição total antes vigente, essas características foram observadas na maioria dos abrigos descritos nos artigos encontrados

Entretanto, já é possível observar outras formas de acolhimento, fora o abrigo. Prada, Williams e Weber (2007) fazem uma análise do funcionamento e rotina de um abrigo e de uma Casa Lar e comparam os dois, tendo com base o ECA.

A definição de Casa Lar, segundo esses autores, se difere da de abrigo por se tratar de um convívio familiar substituto, a família social. Nessa família há uma mãe ou um casal social, com os filhos biológicos, que passam a morar na casa com as crianças acolhidas. Essa casa, com o espaço físico o mais semelhante possível de uma casa, é preparada para uma família e pode acolher uma média de 8 crianças. Além de todas as tarefas operativas, a mãe tem como função agregar afetivamente as crianças.

Muitas diferenças foram observadas nesses dois modelos, entre elas o fato de todas as crianças da Casa Lar terem seus pertences, suas próprias roupas, seus brinquedos, ou seja, têm sua individualidade respeitada. Além disso, $73 \%$ das crianças tinham algum tipo de atividade fora do abrigo, além de maior possibilidade de contato com figuras de afeto constantes (PRADA; WILLIAMS; WEBER, 2007).

Com isso, pode-se ver que existe a possibilidade de se aproximar do que é instituído pelo ECA e sair desse modelo enraizado de instituiçóes totais.

Nota-se que, embora a maioria dos artigos aponte que os abrigos funcionam com caracteristicas de instituiçóes totais, eles ainda podem exercer o papel de suporte para a construção de redes sociais de apoio às crianças institucionalizadas. Para isso, é preciso investir na formaçáo de profissionais que nele trabalhem, no sentido de promover esclarecimentos sobre os objetivos do abrigo e as determinaçōes do ECA e principalmente na quebra de estigmas das crianças abrigadas e suas famílias.

\subsection{Os abrigos em relação ao que preconiza o ECA}

Dos 14 artigos encontrados na pesquisa, apenas um (TINOCO; FRANCO, 2011) não faz referência ao ECA em algum momento do texto.

Esse dado é muito relevante, pois mostra que a realidade atual dos abrigos está sendo problematizada em conformidade com a lei. Se a lei em si não garante seu cumprimento, um dos passos para a mudança efetiva são as pesquisas e publicaçôes sobre o tema.

Contudo, em apenas dois textos o ECA é mencionado por entrevistados (VECTORE; CARVALHO, 2008; NASCIMENTO; LACAZ; ALVARENGA FILHO, 2010). Essa referência não apareceu em nenhum momento na fala das crianças, das cuidadoras/máes sociais ou das famílias. Isso mostra que o ECA ainda não foi apropriado pela população de interesse: crianças, adolescentes, as famílias e os profissionais com quem têm uma convivência diária.

O abrigo, segundo o ECA (Art. 101), é uma medida provisória e excepcional, utilizado apenas em caso de grave risco a sua integridade física ou psíquica (BRASIL, 1990). Todos os esforços devem 
ser feitos no sentido de não afastar a criança do seu convívio familiar (BRASIL, 2008).

Apesar de a falta de recursos materiais náo ser uma das causas de possível abrigamento de crianças e adolescentes, ela aparece como motivo mais recorrente em uma pesquisa do Instituto de Pesquisa Econômica Aplicada (IPEA, 2003), realizada em $2003 \mathrm{em}$ abrigos de todo o Brasil.

[...] estudos recentes sobre o perfil da população de crianças e adolescentes que povoam as instituiçóes de abrigo no Brasil indicam que a pobreza continua a se constituir em motivo (por vezes, o único ou o mais relevante) para a privação do convívio com a família (MAGALHÂES; COSTA; CAVALCANTI, 2011, p. 822).

Vasconcelos, Yunes e Garcia (2009) apresentam relato de profissionais dos abrigos que dizem que o melhor para a criança é a instituição, por esta proporcionar comida, roupa limpa e televisão, concordando com a ideia de que a pobreza é a causa da impossibilidade de retorno à família.

Entretanto, a pesquisa de Magalhães, Costa e Cavalcanti (2011, p. 822) apresenta uma concepção oposta:

Para elas [educadoras de um abrigo] existem hoje milhares de crianças pobres que conseguem ser cuidadas por seus pais biológicos, ficando a salvo de situações de risco como a violência doméstica e o abandono. Por isso, a maioria não concorda com a ideia de que a pobreza possa servir como argumento capaz de justificar a colocação da criança em abrigo.

Galheigo (2003, p. 89), ao realizar uma retrospectiva sobre as perspectivas do acolhimento de crianças, aponta que se historicamente as discussóes sobre a institucionalização de crianças no Brasil, com o Código de Menores e a Política Nacional de Bem-estar do Menor, "[...] trouxeram a pobreza para controle judicial, levando à sua criminalização e à internação da populaçáo jovem pobre [...]", a partir da década de 1980 inicia-se o debate sobre os direitos das crianças, que segue até a promulgação do ECA em 1990, quando se tem a transformação desse paradigma, consolidada com a mudança da "doutrina da situação irregular" (entendida como pobreza) para a "doutrina da proteção integral". Pobreza deixa de ser uma justificativa para a institucionalização infantil.

A lei é muito clara em relação ao caráter provisório do acolhimento institucional, entretanto, diversos autores concordam com o fato de que é comum a longa permanência em abrigos, devido a longos processos de reinserção familiar, a uma atitude passiva do conselho tutelar ou ao fato de não haver preparo ou interesse para que a criança retorne a sua família (AZOR; VECTORE, 2008; VASCONCELOS; YUNES; GARCIA, 2009; NASCIMENTO; LACAZ; ALVARENGA FILHO, 2010; ALTOE; SILVA; PINHEIRO, 2011; NOGUEIRA; COSTA, 2005).

Os programas de reestruturaçáo familiar no sentido de preparar a família para a reinserção da criança ainda estão muito longe de ser uma realidade. Segundo o IPEA (2003), apenas 14\% dos 626 abrigos pesquisados cumpriam todos os critérios observados, como realização de visitas domiciliares, oferta de acompanhamento social, reuniōes ou grupos de discussão e apoio e encaminhamento para programas de auxílio e proteção à familia (INSTITUTO..., 2004). É possível encontrar profissionais que não acreditam no restabelecimento do vínculo com a família, pois desconfiam da qualidade da relaçáo máe e filho (VASCONCELOS; YUNES; GARCIA, 2009, p. 226).

Os profissionais do abrigo enfatizaram suas crenças quanto ao fato de que "o melhor para as crianças é a instituição", pois lá elas recebem até seis refeiçôes por dia, têm roupas limpas e podem assistir à televisão. Isso indica que muitos cuidadores atribuem à situaçâo de pobreza a causa da impossibilidade de retorno das crianças para suas famílias. Além disso, afirmam que as famílias sáo acomodadas a essa situação e que "nunca vão melhorar de vida o suficiente para poder receber as crianças de volta".

Outras questôes relacionadas ao tempo de estadia da criança no abrigo também podem ser levantadas. Segundo as Orientaçōes Técnicas para os Serviços de Acolhimento para Crianças e Adolescentes (BRASIL, 2008), o abrigo deve garantir ambiente e cuidados facilitadores do desenvolvimento e um atendimento personalizado e individualizado, respeitando a autonomia de cada criança acolhida no abrigo.

Apesar de o ECA zelar pela proteção integral, é mais comum observar por parte do abrigo, seus dirigentes e funcionários, uma maior preocupação pela sobrevivência física, ou seja, pela garantia de segurança física, alimentação, sono e higiene, enquanto outras questôes como o desenvolvimento social e intelectual são deixadas em segundo plano (MAGALHĀES; COSTA; CAVALCANTE, 2011).

O desconhecimento e a falta de capacitação dos profissionais são um ponto-chave nessa discussão. Barros e Fiamenghi (2006), Giacomello e Melo (2011), Tinoco e Franco (2011), Vectore e Carvalho 
(2008), Nogueira e Costa (2005) e Azor e Vectore (2008) concordam com o fato de que nos diversos abrigos estudados foram encontrados profissionais despreparados e que não recebem nenhum respaldo ou apoio para lidar com as situaçóes muitas vezes difíceis do cotidiano dos abrigos.

Parece-nos que os comportamentos inapropriados observados nas cuidadoras são, também, conseqüência das próprias fragilidades e inadequaçóes em sua formação técnica, ou melhor, da ausência dessa formação (BARROS; FIAMENGHI FILHO, 2007, p. 1274).

Como pode ser observado, a maioria dos artigos faz uma leitura crítica em relação aos abrigos e ao cumprimento do ECA, enfatizando os aspectos negativos destes.

Contudo, não se pode negar o fato das grandes mudanças proporcionadas pelo ECA. É possível, principalmente no relato das crianças, observar a mudança na visão das crianças do abrigo em relação aos antigos internatos. Enquanto o internato significava uma instituição de punição, privação de liberdade e medo, observam-se na fala das crianças abrigadas hoje sentimentos de segurança, proteção e perspectivas para o futuro.

A criança, no abrigo, percebe-se tendo espaço, boa alimentação, roupas, escola, presentes. Ela tem, em termos de recursos, o que não tinha em casa. Isso é visto claramente em um relato de uma criança na pesquisa de Zem-Mascarenhas e Dupas (2001, p. 418, grifo do autor)

\section{Ahébom, porque eu gosto daqui... brincar, ganhar coisas, ganhar presente, eu faço um monte de coisa... eu brinco no parquinho... porque aqui é grande, eu assisto filme... aqui dá bastante coisa e lá na minha casa não. Lá na minha casa dá pouco.}

O abrigo aparece, junto com a família, no contexto de maior importância na percepção das crianças no estudo de Siqueira et al. (2009). É onde aparece a maioria de seus contatos e sua maior fonte de apoio, uma vez que é nesse contexto que relaçóes de amizade, trocas afetivas, comportamento cooperativos são postos em cena.

Nogueira e Costa (2005) concordam com essa ideia, relatando que é no abrigo que as crianças crescem, formam suas referências, desenvolvem-se e constroem suas histórias. No abrigo encontraram estabilidade, continuidade e regularidade. Também é possível observar na fala das crianças que já saíram do abrigo (AZOR; VECTORE, 2008) uma saudade do tempo em que estiveram na instituição, quando o abrigo representava a família, seja através dos amigos, dos funcionários, da oportunidade de estudo e o estabelecimento de vínculo afetivo.

Porém, o fato de os abrigos estarem se adequando ao previsto pelo ECA e proporcionando melhores condiçôes às crianças que nele estáo náo pode ser entendido como uma justificativa à institucionalizacáo dessas ou ao aumento do tempo de internaçáo. Por isso é tão importante o conhecimento dos direitos das crianças, pois, observam Nogueria e Costa (2005, p. 40), citando Silva e Gueresi (2003),

[...] a ausência de um conhecimento mais amplo do Estatuto da Criança e do Adolescente por parte dos dirigentes de abrigo faz com que os mesmos pautem o atendimento de suas instituiçóes de acordo com suas próprias crenças e prioridades.

Podemos concluir que ainda é incipiente a discussão sobre os objetivos e os critérios de abrigamento instituídos por lei, fazendo com que a concepção higienista do abrigamento infantil ainda seja identificada entre os profissionais que trabalham nessas instituições. É importante ressaltar que a melhora nas práticas de abrigamento náo devem ser justificativas para que a prática se torne mais comum e perca seu caráter de passageiro, uma vez que o convívio familiar e comunitário sempre é a prioridade nas açôes de proteção à criança, segundo o ECA. Mais uma vez, percebe-se que a formação profissional é um caminho a ser seguido na efetivação das propostas do Estatuto para a garantia de cidadania às crianças em situaçôes de vulnerabilidades diversas no Brasil.

\subsection{O estigma de crianças abrigadas: sujeitos de direitos ou massa assujeitada?}

Desde a promulgação do ECA, tem-se instituído, por lei, que as crianças sáo sujeitos de direitos e não objetos de intervenções arbitrárias (BRASIL, 1990).

Contudo, as rotinas rígidas dentro da realidade dos abrigos, a falta de capacitação dos profissionais, $\mathrm{o}$ desconhecimento da lei por parte dos trabalhadores e gestores e o grande número de criança para cada cuidador, acabam por transformar o sujeito em “assujeitado" (SOUSA, 1984 apud NOGUEIRA; COSTA, 2005).

Em diversos momentos nos textos encontrados, as crianças são tratadas como uma massa com características em sua maioria negativas, próprias, sem individualidade, parecendo deixar de lado que são sujeitos com direito a serem tratados com respeito e dignidade. 
Durante os textos, foi possível encontrar diversas características negativas associadas às crianças abrigadas, como: exagerada necessidade de amor, fortes sentimentos de vingança, culpa e depressão, desenvolvimento prejudicado, agressividade, falas ameaçadoras, baixo rendimento escolar, ansiedade e dificuldade de concentração. E seus comportamentos foram generalizados: crianças fogem dos abrigos, brigam com os cuidadores e as outras crianças, não aceitam intervenção e recusam tentativas de aproximação, cuidado e afeto (BARROS; FIAMENGHI JUNIOR, 2007; TINOCO; FRANCO, 2011; MAGALHÂES; COSTA; CAVALCANTE, 2011; NASCIMENTO; LACAZ; ALVARENGA FILHO, 2010).

Entre as educadoras existe a percepçáo de que tem sido frequente a presença de crianças institucionalizadas que se comportam de maneira agressiva, tanto com adultos quanto com seus pares (71,57\%) (MAGALHÃES; COSTA; CAVALCANTE, 2011, p. 825).

Esse estigma vem de todas as esferas. Na entrevista com um gestor de abrigo, relatada por Vectore e Carvalho (2008, p. 444, grifo do autor), este refere-se às crianças abrigadas como "matéria bruta a ser trabalhada" e que "Nós iremos fazer uma experiência com o material humano pior possivel [...]". Além disso, demonstra ter poucas expectativas em relação ao futuro das crianças que apresentam "problemas", como distúrbio de aprendizagem, afirmando que nem todas as pessoas têm condiçóes de cursar um curso superior, entáo têm de ser preparadas de acordo com a sua limitaçáo.

Como se pode notar, o estigma começa dentro do abrigo, mesmo por parte dos gestores, que deveriam estar capacitados para exercer esse cargo. Sobre isso, Magalhães, Costa e Cavalcante (2011), afirmam que a imagem da infância de risco como uma ameaça que se volta à sociedade, e que de algum modo pode causar problemas às pessoas ao seu redor, ainda persiste. Como consequência, o fato de habitar os abrigos acaba por reafirmar a exclusão a que já estavam expostos por estarem fora das formas hegemônicas de viver (NASCIMENTO; LACAZ; ALVARENGA FILHO, 2010).

Em contrapartida, Alexandre e Vieira (2004), ao observarem as crianças em seu brincar livre e sem intervenção dos adultos, notaram características deveras diferentes, quase opostas a estas que estigmatizam. Nesse contexto, foi possível notar as crianças como indivíduos em suas brincadeiras com seus pares. Durante a brincadeira, não apresentaram dificuldade de estar com o outro, de dividir, havendo cooperaçáo e consentimento mútuos.
É nesse momento que elas têm oportunidade de estabelecer suas interaçôes, pois ficam longe da vigilância das atendentes e das represálias. Como não tinha um adulto dizendo o que elas tinham que fazer, as crianças corriam livremente pelo gramado e cooperavam umas com as outras espontaneamente. Um exemplo disto eram as brincadeiras do faz-deconta e os jogos imaginativos. Observou-se que essas brincadeiras permitiam que todas as crianças participassem, não apresentando dificuldade de estar com o outro, dividir com o outro, uma vez que combinavam, sem discutir, os papéis que cada um interpretaria e os brinquedos que utilizariam nas respectivas brincadeiras, havendo assim, cooperação e consentimento mútuos (ALEXANDRE; VIEIRA, 2004, p. 211-212).

Além disso, os mais velhos se responsabilizavam pelos mais novos, ensinando-lhes as brincadeiras e aconselhando-os a ter cuidados. Apresentavam uma relação de carinho, atenção e mostravam preocupação e cuidado com o outro.

É importante dizer que o artigo de Alexandre e Vieira (2004) foi o único que observou a criança no momento de brincar livre, totalmente sem a intervenção do adulto, surgindo assim todas as suas características positivas. Ao ver as crianças livres, com seus pares, sem preconceitos, é possível questionar-se se não são o próprio estigma e preconceito que trazem como resposta a agressividade, a ansiedade, a culpa e outros.

O estigma e a falta de preparo dos cuidadores muitas vezes fazem com que as crianças recebam um tratamento agressivo por parte destes. Infelizmente, essa foi uma conduta amplamente observada nos textos. Apesar de, em geral, a violência não ser física, a agressividade e a humilhação foram registaradas na forma de falar, com xingamentos e ameaças, nas palavras utilizadas, no desrespeito quanto à individualidade e história de vida.

O que se observa é que a cultura do poder e dominação por parte dos educadores do abrigo impera (GIACOMELLO; MELO, 2011). Entre as pesquisas analisadas, foram encontradas práticas de castigo, como privar de comida, remédios e itens básicos como produtos de higiene; tratamentos hostis, não demonstração de afeto, ficar trancado sem fazer nada, e até tratamentos mais agressivos, como apanhar e ajoelhar no milho (BARROS; FIAMENGHI JUNIOR, 2007; AZOR; VECTORE, 2008; NOGUEIRA; COSTA, 2005; PRADA; WILLIAMS; WEBER, 2007; SIQUEIRA et al., 
2009; NASCIMENTO; LACAZ; ALVARENGA FILHO, 2010).

O ECA (BRASIL, 1990), em seu artigo 101, diz que o abrigo é uma medida de proteção a ser acionada quando os direitos da criança são violados, e o CONANDA diz que uma das responsabilidades do cuidador é proteger as crianças e adolescentes (BRASIL, 2008, p. 162).

As crianças, como medida de proteção, são retiradas de sua família e de um ambiente familiar muitas vezes violento, para serem cuidadas, protegidas e acolhidas, entretanto, segundo a maioria dos artigos encontrados nessa pesquisa, não é isso o que vem ocorrendo. Nos abrigos as crianças se deparam com um ambiente violento ${ }^{1}$, assim como em suas casas. Um ambiente que prioriza a ordem e a limpeza em detrimento das brincadeiras, das relaçôes sociais e do afeto.

Em relação a isso, o tratamento das crianças no abrigo como objetos de tutela é evidente em alguns dos textos (NASCIMENTO; LACAZ; ALVARENGA FILHO, 2010; PRADA; WILLIAMS; WEBER, 2007; NOGUEIRA; COSTA, 2005; AZOR; VECTORE, 2008). Eles relatam que muitas vezes a criança não tem o direito à autonomia de gerir seu cotidiano, não tem direito a ter seus próprios pertences ou de tomar pequenas decisóes sobre sua vida ou sua rotina.

Constata-se, então, que a criança é obrigada a assumir uma posição passiva em relação ao adulto, ficando submissa a seus gestos e manipulaçôes, podendo ser difícil que se desenvolva no abrigo um "eu" desejoso e pensante (NOGUEIRA; COSTA, 2005; AZOR; VECTORE, 2008).

Prada, Williams e Weber (2007) dizem que o funcionamento de um abrigo que priva a criança de um espaço de individualidade está interferindo na possibilidade de desenvolvimento de um adulto autônomo e capaz de uma vida independente.

O artigo de Nascimento, Lacaz e Alvarenga Filho (2010) é o único que cita um direcionamento de açóes no sentido de dar mais voz às crianças e de promover açôes para que elas conheçam seus direitos e participem das decisóes. Em duas entrevistas com profissionais de diferentes abrigos, há relatos de assembleias com participação das crianças, adolescentes e funcionários nas decisões da casa. Uma das entrevistadas dá um relato que explica claramente a importância dessas assembleias:

Mas é uma experiência assim muito boa quando você começa a construir um espaço onde dá direito de voz a todos e não só a um grupo, só às educadoras ou só à equipe técnica, mas quando você tenta fazer com que esse espaço seja todo tempo avaliado por todos os atores que estão ali dentro. É o ator que está ali dentro, não são só os educadores e os meninos, mas é o vizinho, é a escola, são os voluntários, quer dizer, cada pessoa que está envolvida direta ou indiretamente com aquele espaço, com aquele abrigo [...]. Consegue ver ou fazer com que a criança passe aquele período no abrigo da forma mais digna possível: dando direito de voz a ela. E o direito à voz é o direito de querer ficar e de não querer ficar também, de querer sair do abrigo. Então, eu sempre falei com as crianças e com os educadores que isso aqui não é uma prisão, aqui é um espaço de acolhimento, onde o menino tem que estar aqui porque ele gosta. Porque na hora de ir para escola, ele vai para escola sozinho. Ele tem que ir para escola e tem que querer voltar para o abrigo (NASCIMENTO; LACAZ; ALVARENGA FILHO, 2010, p. 57-58).

É importante que essas ações sejam incentivadas e estimuladas. A criança que está consciente dos seus direitos, e que tem poder de participaçáo e voz nas decisões do espaço onde vive, não será um sujeito tutelado. Só assim ela poderá exercer sua autonomia e cidadania, e conquistar todos os direitos que lhe são garantidos.

Essas crianças, muitas vezes abandonadas pela família, pela sociedade e pelo Estado, podem encontrar no protagonismo, no conhecimento dos seus direitos, na troca de informaçãos com pares e adultos, um empoderamento, convertendo-as em sujeitos e atores sociais (REYES et al., 2008)

\section{Conclusão}

Considera-se que, diante dos dados encontrados nessa revisão de literatura, ainda hoje a realidade dos abrigos brasileiros não atingiu o proposto pelo ECA.

Analisar as características de instituiçóes totais nos abrigos, a adequação às determinaçóes do ECA e o estigma das crianças abrigadas, apontam que muito ainda deve ser feito para que as mudanças propostas pelo ECA sejam efetivamente consolidadas. Muitos abrigos ainda funcionam na lógica institucional, com característica de fechamento como as instituiçôes totais, além de existir uma visão estigmatizada das crianças e seus familiares por parte da própria equipe desses espaços.

A lei é um dispositivo importante, porém, é apenas um primeiro passo para mudanças efetivas. As publicaçôes encontradas nessa revisão levantam essa questão aos profissionais envolvidos nesse 
contexto, atentando para a importância do ECA e a discrepância que há entre a lei e a realidade.

A partir daí, iniciativas devem surgir para que verdadeiras mudanças possam ocorrer. Ao longo da análise dos textos, foi possível perceber que umas das principais questôes é quanto à percepção do abrigo e do abrigado. Para isso, o abrigo deve deixar de ser visto como uma instituição total e passar a ser visto como um local de morada substituta, onde o modelo de lar e família deve ser reproduzido, e a criança como um sujeito de direitos e náo como um abrigado.

Percebemos ser necessária a capacitação e a informação de todos os profissionais envolvidos com o acolhimento institucional, direta ou indiretamente. $\mathrm{O}$ empoderamento das próprias crianças e sua conscientização a respeito de seus direitos são uma questão a ser trabalhada.

\section{Referências}

ALEXANDRE, D. T.; VIEIRA, M. L. Relaçáo de apego entre crianças institucionalizadas que vivem em situação de abrigo. Psicologia em Estudo, Maringá, v. 9, n. 2, p. 207-2017, 2004.

ALTOE, S.; SILVA, M.; PINHEIRO, B. S. A inconstância dos laços afetivos na vida das crianças e adolescentes abrigados. Revista Psicologia Política, São Paulo, v. 11, n. 21, p. 109-122, 2011.

AYRES, L. S. M. et al. Abrigos e abrigados: construção e descontrução de um estigma. Estudos e Pesquisas em Psiologia, Rio de Janeiro, v. 10, n. 2, p. 420-433, 2010.

AZOR, A. M. G. C. V.; VECTORE, C. Abrigar/desabrigar: conhecendo o papel das famílias nesse processo. Estudos de Psicologia, Campinas, v. 25, n. 1, p. 77-99, 2008.

BARROS, D. D.; LOPES, R. E.; GALHEIGO, S. M. Terapia ocupacional social: concepçóes e perspectivas. In: CAVALCANTI, A.; GALVÃO, C. Terapia Ocupacional: fundamentação e prática. Rio de Janeiro: Guanabara Koogan, 2007. p. 347-353.

BARROS, R. C.; FIAMENGHI JUNIOR, G. A. Interaçôes afetivas de crianças abrigadas: um estudo etnográfico. Revista Ciência \& Saúde Coletiva, Rio de Janeiro, v. 12, n. 5, p. 1267-1276, 2007.

BOURDIEU, P. A dominação masculina. Rio de Janeiro: Bertrand Brasil, 1999.

BRASIL. Estatuto da criança e do adolescente. Rio de Janeiro: Conselho Nacional de Defesa da Criança e do Adolescente, 1990.

BRASIL. Ministério do Desenvolvimento Social e Combate à Fome. Orientaçōes Técnicas Para os Serviços de Acolhimento de Crianças e Adolescentes. Brasília: CNAS; Conanda, 2008.
GALHEIGO, S. M. O abrigo para crianças e adolescentes: consideraçóes acerca do papel do terapeuta ocupacional. Revista de Terapia Ocupacional da Universidade de São Paulo, São Paulo, v. 14, n. 2, p. 85-94, 2003.

GIACOMELLO, K. J.; MELO, L. L. Do faz de conta à realidade: compreendendo o brincar de crianças institucionalizadas vítimas de violência por meio do brinquedo terapêutico. Revista Ciência \& Saúde Coletiva, Rio de Janeiro, v. 16, p. 1571-1580, 2011. Suplemento 1.

GOFFMAN, E. Estigma - notas sobre a manipulação da identidade deteriorada. Rio de Janeiro: Zahar Editores, 1980.

GOFFMAN, E. Manicômios, prisóes e conventos. São Paulo: Perspectiva, 2001.

INSTITUTO DE PESQUISA ECONÔMICA APLICADA - IPEA. Levantamento nacional de abrigos para crianças e adolescentes da rede SAC. Brasília, 2003.

MAGALHÂES, C. M. C.; COSTA, L. N.; CAVALCANTE, L. I. C. Percepçáo de educadores de abrigo: o seu trabalho e a criança institucionalizada. Revista Brasileira de Crescimento e Desenvolvimento Humano, São Paulo, v. 21, n. 3, p. 818-831, 2011.

MALFITANO, A. P. S.; SILVA, T. V. Abrigo como medida de proteção para crianças. Revista de Terapia Ocupacional da Universidade de São Paulo, São Paulo, v. 25, n. 1, p. 94-100, 2014.

NASCIMENTO, M. L.; LACAZ, A. S.; ALVARENGA FILHO, J. R. Entre efeitos e produçôes: ECA, abrigos e subjetividades. Barbaro, Santa Cruz do Sul, v. 2, n. 33, p. 50-64, 2010.

NERY, M. A. A convivência familiar e comunitária é direito da criança e do adolescente e uma realidade a ser repensada pela escola. Cadernos Cedes, Campinas, v. 30, n. 81 , p. $189-207,2010$

NOGUEIRA, P. C.; COSTA, L. F. Mãe social: profissão? função materna? Estilos da Clínica, São Paulo, v. 10, n. 19, p. 162-181, 2005.

PRADA, C. G.; WILLIAMS, L. C. A.; WEBER, L. N. D. Abrigos para crianças vítimas de violência doméstica: funcionamento relatado pelas crianças e pelos dirigentes. Revista Psicologia: Teoria e Prática, São Paulo, v. 9, n. 2, p. 14-25, 2007.

REYES, G. et al. Promoção da participação protagônica e significativa de crianças e adolescentes expostos à violência. London: Save The Children Suécia, 2008.

SIQUEIRA, A. C. et al. Percepção das figuras parentais na rede de apoio de crianças e adolescentes institucionalizados. Revista Arquivos Brasileiros de Psicologia, Rio de Janeiro, v. 61, n. 1, p. 176-190, 2009.

TINOCO, V.; FRANCO, M. H. P. O luto em instituiçôes de abrigamento de crianças. Estudos de Psicologia, Campinas, v. 28, n. 4, p. 427-434, 2011. 
VASCONCELOS, Q. A.; YUNES, M. A. M.; GARCIA, N. M. Um estudo ecológico sobre as interaçóes da família com o abrigo. Paidéia, Ribeirão Preto, v. 19, n. 43, p. 221-229, 2009.

VECTORE, C.; CARVALHO, C. Um olhar sobre o abrigamento: a importância dos vínculos em contexto de abrigo. Revista Psicologia Escolar e Educacional, Campinas, v. 12, n. 2, p. 441-449, 2008.

ZEM-MASCARENHAS, S. H.; DUPAS, G. Conhecendo a experiência de crianças institucionalizadas. Revista da Escola de Enfermagem da USP, São Paulo, v. 35, n. 4, p. 413-419, 2001.

\section{Contribuição dos Autores}

Ambas autoras contribuiram igualmente na concepção do artigo e aprovaram a versão final do texto.

\section{Notas}

${ }^{1}$ Muitas vezes nos abrigos as crianças sofrem a chamada violência simbólica, definida por Bourdieu (1999, p. 7-8) como aquela "[...] que se exerce essencialmente pelas vias puramente simbólicas da comunicação e do conhecimento, ou, mais precisamente, do desconhecimento, do reconhecimento, ou, em uma última instância, do sentimento [...]”. Essa violência muitas vezes náo é reconhecida como tal, tanto pelos que a sofrem como pelos que a exercem. 